Keywords: colorectal cancer screening; cancer prevention; non-participation; faecal immunochemical test; lifestyle; multiple screening rounds; discontinuation

\title{
Lifestyle predictors for non-participation and outcome in the second round of faecal immunochemical test in colorectal cancer screening
}

Markus Dines Knudsen*,1,2,3 ${ }^{*}$ Paula Berstad ${ }^{1}$, Anette Hjartåker ${ }^{3}$, Elisabeth Haagensen Gulichsen ${ }^{4}$, Geir Hoff ${ }^{1,2,5}$, Thomas de Lange ${ }^{1,6}$, Tomm Bernklev ${ }^{2,7,8}$ and Edoardo Botteri ${ }^{1,9}$

${ }^{1}$ Department of Bowel cancer screening, Cancer Registry of Norway, P.O. Box 5313, Majorstuen, Oslo 0304, Norway; ${ }^{2}$ Department of Research and Development, Telemark Hospital, Ulefosseveien 55, Skien 3710, Norway; ${ }^{3}$ Department of Nutrition, Institute of Basic Medical Sciences, University of Oslo, Blindern, P.O. Box 1046, Oslo 0317, Norway; ${ }^{4}$ Department of Gastroenterology, Ostfold Hospital Trust, Moss P.O. Box 1714, Sarpsborg 1714, Norway; ${ }^{5}$ Department of Health Management and Health Economics, Institute of Health and Society, University of Oslo, Blindern P.O. Box 1089, Oslo 0317, Norway; ${ }^{6}$ Department of Medicine, Bærum Hospital, Vestre Viken Hospital Trust, Sandvika, P.O. Box 800, Drammen 3004, Norway; ${ }^{7}$ Institute of Clinical Medicine, University of Oslo, Blindern P.O. Box 1171, Oslo 0318, Norway; ${ }^{8}$ Research and Development, Vestfold Hospital, Vestfold Hospital Trust, Tønsberg, P. O. 2168, Tønsberg 3103, Norway and 'National Advisory Unit for Women's Health, Women's Clinic, Oslo University Hospital, Oslo 0424, Norway

Background: To reduce colorectal cancer (CRC) mortality through population-based screening programmes using faecal tests, it is important that individuals continue to participate in the repeated rounds of screening. We aimed to identify lifestyle predictors for discontinuation of faecal immunochemical test (FIT) screening after the first round, as well as lifestyle predictors for colorectal neoplasia detected in the second-round FIT screening.

Methods: In this longitudinal study, we invited 6959 individuals aged 50-74 years from south-east Norway for a first round of FIT screening and to complete a self-reported lifestyle questionnaire on demographic factors, body mass index (BMl, $\mathrm{kg} \mathrm{m}^{-2}$ ), smoking habits, physical activity, consumption of alcohol and dietary items. Two years later, we estimated the associations between these factors, non-participation and screening results in the second round of FIT screening using adjusted odds ratios (ORs) and 95\% confidence intervals (Cls).

Results: Of the 3114 responders to the questionnaire who completed the first-round FIT and who were invited to participate in second-round FIT screening, 540 (17\%) did not participate. The OR and (95\% Cl) for discontinuation of FIT screening after the first round was 1.61 (1.24-2.10) for current smoking compared with non-smoking; 2.01 (1.25-3.24) for BMI $\geqslant 35 \mathrm{~kg} \mathrm{~m}^{-2}$ compared with BMI $16.9-24.9 \mathrm{~kg} \mathrm{~m}^{-2}$ and $0.70(0.52-0.94)$ for physical activity in the third quartile vs the first. Among participants, smoking, high $\mathrm{BMI}$ and high alcohol consumption were associated with an increased odds of detecting colorectal neoplasia $(n=107)$.

Conclusions: These results may indicate that Norwegian FIT screening participants who discontinue after the first round have lifestyle behaviours associated with increased risk of CRC.

*Correspondence: MD Knudsen; E-mail: markus.knudsen@Kreftregisteret.no

Received 18 April 2017; revised 30 May 2017; accepted 31 May 2017; published online 13 July 2017

(C) 2017 Cancer Research UK. All rights reserved 0007-0920/17 
Screening for colorectal cancer (CRC) using faecal occult blood tests reduces CRC mortality (Scholefield et al, 2012; Chiu et al, 2015). It is recommended to repeat the test every other year due to limited sensitivity for the detection of adenomas and CRC (de Wijkerslooth et al, 2012; Brenner et al, 2014). Nevertheless, only $38-48 \%$ of the invited subjects consistently participate in all multiple screening rounds (Crotta et al, 2012; Steele et al, 2014; Lo et al, 2015; van der Vlugt et al, 2017). Consequently, it is desirable to identify predictors of non-participation in order to plan interventions to increase the participation and consequently the efficiency of CRC screening (Cole et al, 2012).

Previous studies have suggested that non-participation in multiple screening rounds is associated with low socioeconomic status, younger age, male gender and previous use of faecal occult blood test (FOBT) (Seeff et al, 2004; Weber et al, 2008; Pornet et al, 2014; Lo et al, 2015; van der Vlugt et al, 2017). Furthermore, nonparticipation in first-round FOBT has been associated with current smoking, body mass index $\left(\mathrm{BMI}, \mathrm{kg} \mathrm{m}^{-2}\right.$ ) $>30$, low physical activity and high alcohol intake in a British study (Blanks et al, 2015). These are all lifestyle factors that have been associated with increased risk of colorectal neoplasia (Botteri et al, 2008; Kirkegaard et al, 2010; WCRF/AICR, 2011; Wolin et al, 2011; Hong et al, 2012; Aune et al, 2013; Aleksandrova et al, 2014; Ben et al, 2014; Norat et al, 2014; Zhu et al, 2014).

Nevertheless, there is a limited knowledge whether these lifestyle factors also are associated with non-participation in multiple CRC screening rounds. Assessing lifestyle behaviours at screening may help to identify individuals at higher risk for discontinuing the screening and for colorectal neoplasia.

The primary aim of the present study was to identify independent lifestyle predictors for non-participation in the second round of faecal immunochemical test (FIT) screening among firstround participants (i.e., discontinuation of FIT after the first round). Our secondary aim was to investigate whether these lifestyle predictors also were associated with detection of colorectal neoplasia in those who participated in the second round of FIT screening.

\section{MATERIALS AND METHODS}

Study population. The present longitudinal study is a lifestyle substudy within the ongoing Bowel Cancer Screening in Norway (BCSN), a pilot study of a national CRC screening programme. The BCSN is a randomised controlled trial that compares five biennial rounds of FIT to a single sigmoidoscopy. A total of 140000 women and men aged 50-74 years (at the time of randomisation) from two geographically defined areas in southeast Norway were randomly assigned (1:1 ratio) to one of the two screening modalities. Invitations were scheduled from 2012 to 2018 (Bretthauer and Hoff, 2012; de Lange et al, 2017).

In the present study, only participants in the FIT arm who had also been invited to the lifestyle substudy and participated in the first round of FIT screening were included. From November 2012 to September 2013, 6959 individuals were invited (Knudsen et al, 2016). The individuals were sent a two-page lifestyle questionnaire (LSQ) along with an invitation to participate in FIT-based CRC screening with a self-administrated FIT kit. The LSQ was to be completed on paper or online before receiving the results of the first FIT screening. Participants with a negative first-round FIT screening were mailed a second FIT kit 2 years after the first one but this time without an LSQ. They had to return the secondround FIT kit before May 2016 to be considered participants of the second-round FIT screening in the present study. Non-participants were sent a reminding letter for both rounds of FIT but not for the LSQ (Figure 1).
Screening. A FIT test result of $\geqslant 75 \mu \mathrm{g}$ haemoglobin $1^{-1}$ buffer was considered positive. In the present study, results were based on the second of five biennial rounds of FIT screening. Participants with a positive FIT were referred for a work-up colonoscopy. Based on the findings at the work-up colonoscopy, participants were categorised into the following categories: no adenoma (negative findings, non-neoplastic findings, other polyps); colorectal neoplasia (any adenoma and CRC). Eleven participants with a positive FIT screening result did not participate in the work-up colonoscopy and were excluded from the analyses of colorectal neoplasia (Figure 1).

Exclusion criteria. Participants were excluded at baseline and during follow-up due to medical reasons (e.g., severe heart, lung or liver diseases, cancer with life expectancy $<1$ year), previous CRC, relocating out of the screening municipalities or previous colonoscopy in the last 12 months. Participants with a positive first-round FIT screening result were not invited to the secondround FIT screening and are not included in the present study. Furthermore, participants were also excluded if the LSQ was completed after receiving the test result from the first round of FIT or if it was not possible to determine the timing between the LSQ and the first FIT screening results. Two persons moved, four died and six withdrew from the screening project before the invitation to the second-round FIT screening was sent. Six persons were not invited owing to a delay in the study (Figure 1).

Lifestyle questionnaire. The LSQ consisted of questions used in previous national surveys (Johansson et al, 1998; Norwegian Institute of Public Health, 2016) and the Norwegian Colorectal Cancer Prevention study (Larsen et al, 2006; Berstad et al, 2015). The participants were asked about demographic factors as well as lifestyle factors.

Demographic factors. The participant's ethnicity based on her/his parent's birthplace was dichotomised as native (Norway) or nonnative (any other country). Marital status was dichotomised as married/cohabiting or non-married/-cohabiting. Education length was categorised as primary school, high school or a minimum of 2 years at university/college. Occupation was categorised as working, retired, unemployed/homemakers or disabled/on rehabilitation.

Lifestyle factors. Individuals were divided into three groups on smoking status: current smokers (daily and occasional), former smokers, and never smokers. BMI was calculated from selfreported weight $(\mathrm{kg})$ and height $(\mathrm{cm})$ and categorised according to international standards: $18.5-24.9 \mathrm{~kg} \mathrm{~m}^{-2}, \quad 25.0-29.9 \mathrm{~kg} \mathrm{~m}^{-2}$, $30.0-34.9 \mathrm{~kg} \mathrm{~m}^{-2}$ (obesity class I) and $35-65 \mathrm{~kg} \mathrm{~m}^{-2}$ (obesity class II and III) (World Health Organization, 2016). Seventeen participants with BMI between 16.9 and $18.5 \mathrm{~kg} \mathrm{~m}^{-2}$ were included in the normal-weight category (BMI $18.5-24.9 \mathrm{~kg} \mathrm{~m}^{-2}$ ). Physical activity (times per week of $30 \mathrm{~min}$ of activity) was calculated by adding the responses to the two questions on physical activity frequency: (1) without sweating or shortness of breath and (2) so that you sweat or get short of breath. The reply options ranged from 'never' to 'more than seven times per week of at least 30 min physical activity'. The total physical activity level was divided into gender-specific quartiles. Alcohol consumption was assessed by two questions: (1) 'How often have you consumed alcohol during the last year?' with reply options that ranged from 'never' to 'four to seven times per week' and (2) 'When consuming alcohol, how many glasses do you usually have?' The answers of the two questions were multiplied and divided into gender-specific quartiles. Non-drinkers were categorised into a fifth category. Servings of fruits, berries and vegetables, assessed by three separate questions regarding (1) fruits and berries, (2) raw vegetables and (3) boiled vegetables were summed to total consumption of fruits 


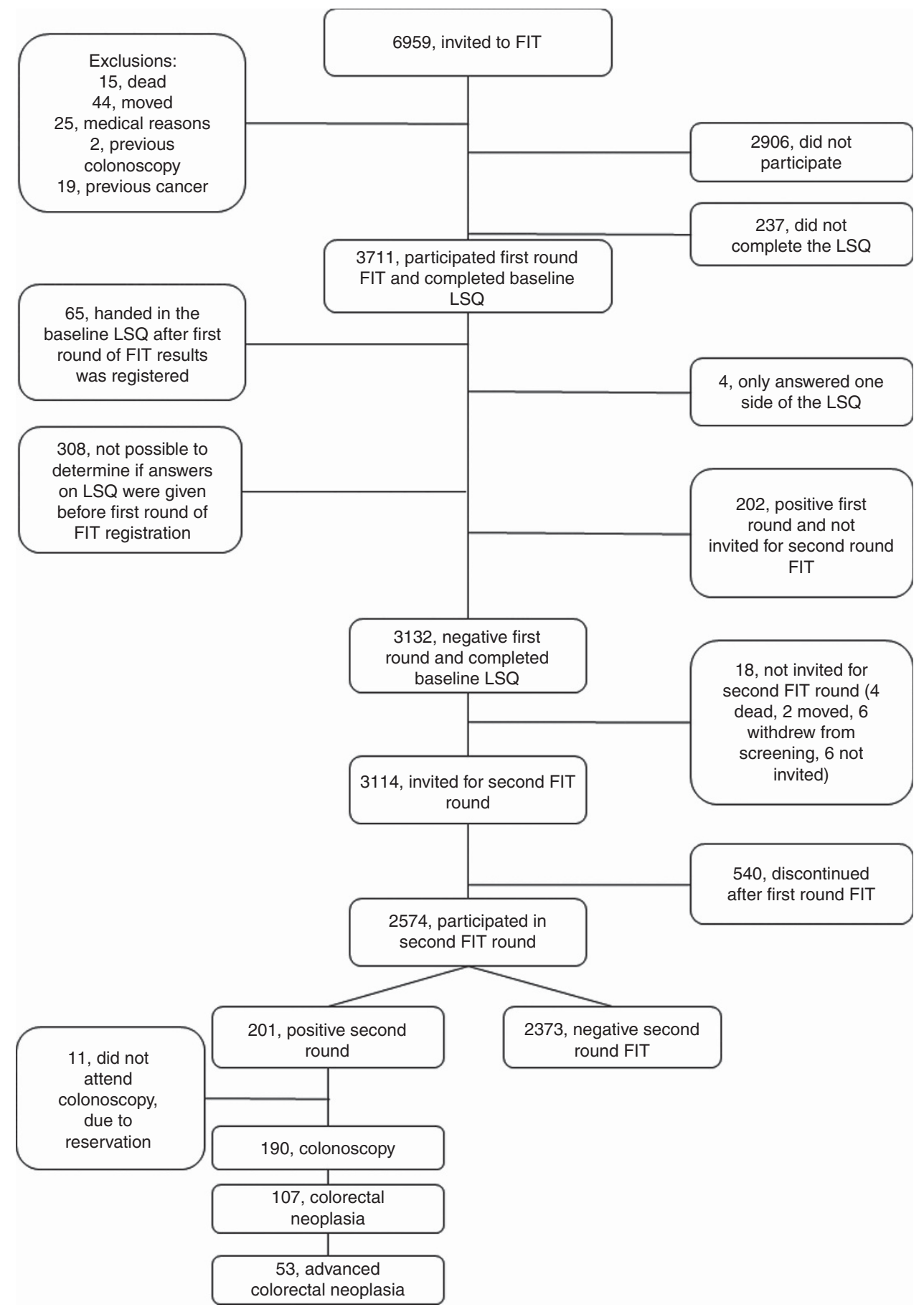

Figure 1. Flow chart for participation in second-round faecal immunochemical test (FIT) colorectal cancer (CRC) screening and response to the lifestyle questionnaire (LSQ) at baseline in the lifestyle substudy of the bowel cancer screening in Norway: a pilot study.

and vegetables (F\&V, servings per day). Servings of total red and processed meat for dinner ( $\&$ P meat, servings per week) was assessed by summing the three questions on the number of servings of (1) steak, pork chops or similar, (2) hamburgers or other dishes with minced meat and (3) sausages. Consumption of fatty fish was assessed by one question. Six frequency alternatives ranging from 'seldom/never' to 'more than three servings per day' were available options for the dietary questions. Each of the dietary factors was divided into gender-specific quartiles to create a dietary score (ranging from 0 to 3 ). One point was given for each of the following criteria: consumption of total R\&P meat in the first or second quartile; total F\&V in the third or fourth quartile; and fatty fish in the third or fourth quartile. Owing to the frequency categories in the LSQ, it was not possible to divide the variables into equally sized quartiles.

Lifestyle score. A lifestyle score was created based on the following factors: smoking habits, BMI, physical activity, and consumption of alcohol, F\&V, R\&P meat and fatty fish. Each of the single lifestyle factors was dichotomised to reflect adherence to health recommendations (World Health Organization, 2003; The Norwegian Directory of Health, 2011; Nordic Council of Ministers, 2012). Each participant was assigned one point for each fulfilled lifestyle criterion except F\&V and fish, for which both had to be fulfilled to earn one point. The total number of points in the lifestyle score ranged from zero (poorest) to six (best). More 
detailed information on the lifestyle score has been published elsewhere (Knudsen et al, 2016).

Statistical analyses. Baseline characteristics are presented as percentages. Chi-square test and chi-square test for trend were used to examine the association between the independent variables and dichotomous variables, that is, non-participation and colorectal neoplasia. Multivariable logistic regression analyses were used to estimate odds ratios (ORs) with 95\% confidence intervals (CI) for the association between the individual variables and not participating in the second-round FIT screening and the association between individual variables and the odds of detecting colorectal neoplasia after a positive second-round FIT screening. Inclusion of covariates in the multivariable models was based on $a$ priori knowledge and statistical information $(P \leqslant 0.1$ in the crude chi-square tests). The statistical models for non-participation and for colorectal neoplasia included the following covariates: age, sex, screening centre, working status, educational length, marital status, ethnic background, smoking, BMI, physical activity, alcohol consumption, and the diet score. The statistical models including the lifestyle score were adjusted for age, sex, screening centre, working status, educational length, marital status and ethnic background. Interactions between gender and the various variables were examined in sensitivity analysis.

Missing values were handled by using multiple imputation. We made the assumption that values were missing at random, as tests with missing data indicators did not show any associations with the outcome variables. Twenty data sets were imputed to reduce sampling variability from the imputation process (Horton and Lipsitz, 2001). We imputed missing variables used in the logistic regression models using the following variables: discontinuation of FIT screening after the first round (yes/no), screening centre, age, and gender. The same variables were used for imputation in the analysis on colorectal neoplasia (yes/no). Sensitivity analyses were carried out using complete case analysis and missing indicator method in separate logistic regression models. Owing to few cases of advanced colorectal neoplasia $(n=53)$, colorectal neoplasia was used as an end point in the present paper. Furthermore, predictors for advanced colorectal neoplasia detected at the first-time screening by FIT and sigmoidoscopy in the present screening pilot study have been addressed previously (Knudsen et al, 2016).

Analyses were performed independently by MDK using the STATA software, version 14.1 (Stata Corp, College Station, TX, USA) and by EB, using the SAS software, version 9.4 (SAS Institute, Cary, NC, USA) and the R software, version 3.2.4 (http:// cran.r-project.org/). The STATA MI command was used for multiple imputation.

Ethics approval. The Regional Research Ethics Committee of southeast Norway and the Norwegian Data Inspectorate approved the study protocol (approval no. 2011/1272). The participants gave their consent to participate in the lifestyle study by completing and returning the mailed questionnaire.

\section{RESULTS}

Overall, 3114 individuals were invited to the second-round FIT screening. Their mean age was 61.6 years (6.8 s.d.), and $47 \%$ were males. Of these, 2574 (83\%) returned the second-round FIT kit, while $540(17 \%)$ did not and were registered as non-participants in the second-round FIT screening. Of the 2574 participating in the second-round FIT screening, 201 (8\%) had a positive FIT, of whom 190 (95\%) participated in the work-up colonoscopy. One hundred and seven (56\%) individuals were diagnosed with colorectal neoplasia (Figure 1).

Demographic characteristics for discontinuation of FIT screening after the first round are shown in Table 1. The ORs for discontinuation was 1.98 (95\% CI: $1.22-3.20$ ) for age $50-54$ years and 1.65 (95\% CI: 1.02-2.66) for age 55-59 years compared with age 70-74 years 1.51 (95\% CI: 1.23-1.86) for male compared with female gender and 1.50 (95\% CI: 1.05-2.15) for non-native compared with native ethnic background. The odds for demographic predictors of colorectal neoplasia detected after a positive second-round FIT screening are shown in Table 2. The ORs for colorectal neoplasia was 3.59 (95\% CI: 1.42-9.12) for age 60-64 years, 5.03 (95\% CI: 1.91-13.28) for age 65-69 years and $6.40(95 \%$ CI: 2.16-18.93) for age 70-74 years compared with age 50-54 years.

Lifestyle characteristics for discontinuation of FIT screening after the first round are shown in Table 1. The ORs for discontinuation was 1.61 (95\% CI: 1.24-2.10) for current smoking compared with non-smoking and 2.01 (95\% CI: 1.25-3.24) for $\mathrm{BMI}>35 \mathrm{~kg} \mathrm{~m}^{-2}$ compared with BMI $16.9-24.9 \mathrm{~kg} \mathrm{~m}^{-2}$. In addition, individuals reporting physical activity within the third quartile had an OR of 0.70 (95\% CI: 0.52-0.94) for discontinuing the FIT screening compared with individuals in the first quartile. No significant associations between the dietary score and discontinuation were observed. No significant trend was observed between the lifestyle score and discontinuation of FIT after the first round ( $P$-value 0.08: Figure $2 \mathrm{~A})$. The ORs for colorectal neoplasia detected after a positive second-round FIT screening by lifestyle factors are shown in Table 2. The ORs for colorectal neoplasia was 2.13 (95\% CI: 1.20-3.77) for current smoking compared with nonsmoking, 4.09 (95\% CI: $1.53-10.96)$ for $\mathrm{BMI}>35 \mathrm{~kg} \mathrm{~m}^{-2} \mathrm{com}-$ pared with a BMI $16.9-24.9 \mathrm{~kg} \mathrm{~m}^{-2}$ and 2.07 (95\% CI: $1.09-3.96$ ) for alcohol consumption within the fourth quartile compared with the first quartile. No significant associations between the dietary score and colorectal neoplasia detected after a positive secondround FIT screening were observed. The trend for odds of colorectal neoplasia across the lifestyle score categories was not significant $(P$-value $=0.2$; Figure $2 \mathrm{~B})$.

When stratifying by sex, BMI and smoking were predictors of discontinuation of FIT after the first round for both women and men. Being disabled/on rehabilitation were significant predictors of discontinuation of FIT after the first round in men only and age in women only (Supplementary Table S1). Despite these differences between sexes, we observed no significant interaction between gender and any of the various factors (results not shown).

Results from the separate sensitivity analyses using (a) the complete cases only and (b) missing indicator method did not differ from the presented results using multiple imputations. The proportion of current smokers was 26 and $12 \%$ in those with the lowest and the highest education, respectively. The proportion of obese individuals was 21 and $11 \%$ in those with the lowest and the highest education, respectively.

\section{DISCUSSION}

In the present study, we observed that the unfavorable lifestyle factors: smoking, obesity classes II and III, and low physical activity, were associated with discontinuing FIT screening after the first round, when adjusted for demographic factors. Smoking and obesity classes II and III were associated with increased odds of colorectal neoplasia detected at second-round FIT screening. Additionally, individuals reporting high alcohol consumption had increased odds of colorectal neoplasia.

To the best of our knowledge, this is the first study investigating both independent lifestyle and demographic predictors for discontinuing FIT screening after the first round and colorectal neoplasia detected in the second-round FIT screening in individuals who tested negative in the first FIT round. Studies investigating discontinuation of repeated CRC screening after the 
Table 1. Characteristics with adjusted odds ratio (OR) and $95 \%$ confidence intervals (Cls) for individuals continuing and discontinuing second-round faecal immunochemical test (FIT)-based colorectal cancer (CRC) screening after the first round, $N=3114$

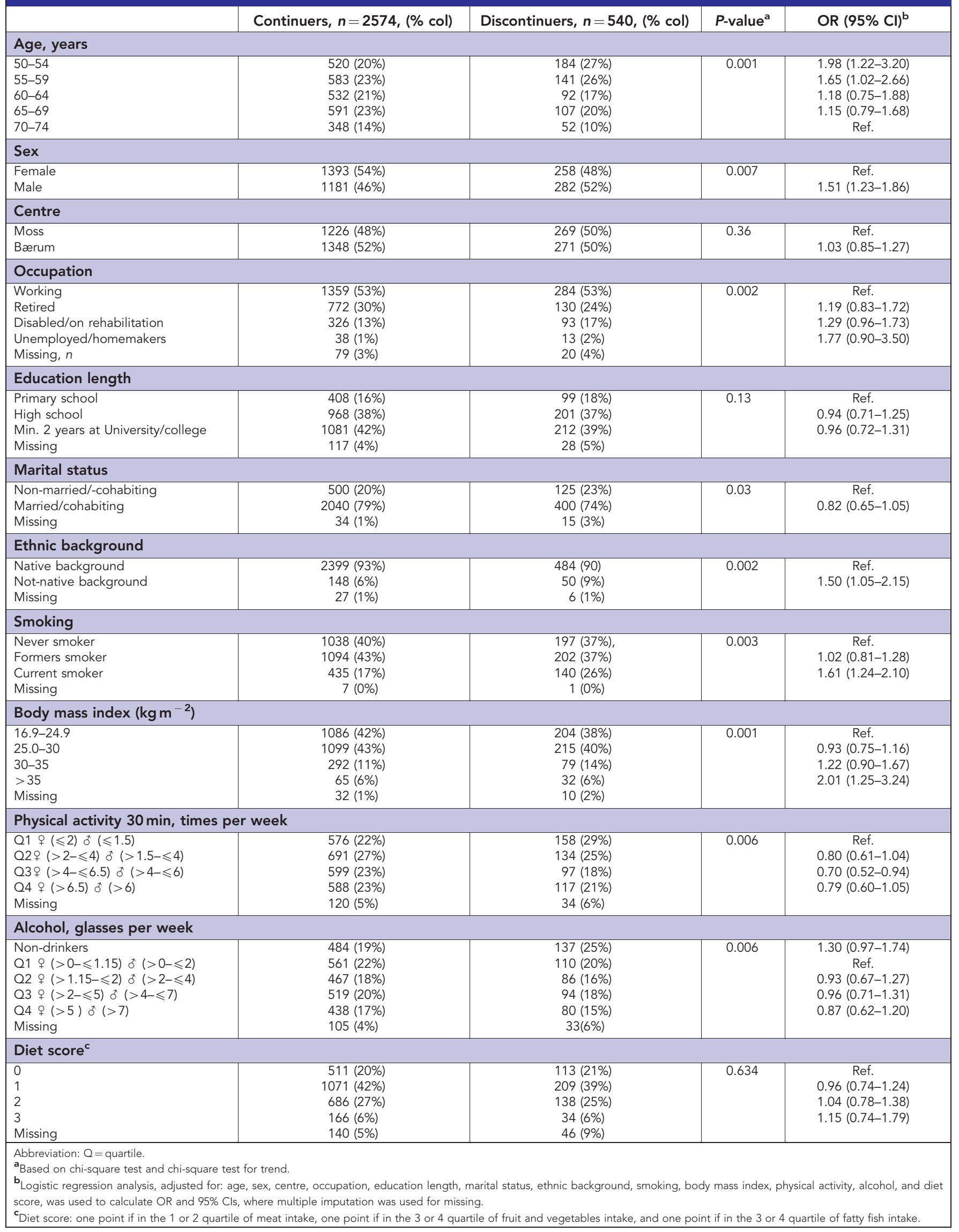


Table 2. Participant characteristics with odds ratio (OR) and $95 \%$ confidence intervals (Cls) for colorectal neoplasia detected after a positive second-round faecal immunochemical test (FIT)-based colorectal cancer screening, $N=2563$

\begin{tabular}{|c|c|c|c|c|}
\hline & $\begin{array}{l}\text { No adenomas/negative FIT, } \\
n=2456,(\% \text { col })\end{array}$ & $\begin{array}{c}\text { Colorectal neoplasia, } \\
n=107,(\% \text { col })\end{array}$ & $P$-value ${ }^{a}$ & OR $(95 \% \mathrm{Cl})^{\mathrm{b}}$ \\
\hline \multicolumn{5}{|l|}{ Age, years } \\
\hline $\begin{array}{l}50-54 \\
55-59 \\
60-64 \\
65-69 \\
70-74\end{array}$ & $\begin{array}{l}514(21 \%) \\
562(23 \%) \\
508(21 \%) \\
552(22 \%) \\
320(13 \%)\end{array}$ & $\begin{array}{c}6(6 \%) \\
18(17 \%) \\
22(21 \%) \\
37(35 \%) \\
24(22 \%)\end{array}$ & 0.001 & \begin{tabular}{l}
\multicolumn{1}{c}{ Ref. } \\
$2.52(0.99-6.46)$ \\
$3.59(1.42-9.12)$ \\
$5.03(1.91-13.28)$ \\
$6.40(2.16-18.93)$
\end{tabular} \\
\hline \multicolumn{5}{|l|}{ Centre } \\
\hline $\begin{array}{l}\text { Moss } \\
\text { Bærum }\end{array}$ & $\begin{array}{l}1173(48 \%) \\
1283(52 \%)\end{array}$ & $\begin{array}{l}48(45 \%) \\
59(55 \%)\end{array}$ & 0.56 & $\begin{array}{c}\text { Ref. } \\
1.13(0.74-1.73)\end{array}$ \\
\hline \multicolumn{5}{|l|}{ Occupation } \\
\hline $\begin{array}{l}\text { Working } \\
\text { Retired } \\
\text { Disable/on rehabilitation } \\
\text { Unemployed/homemakers } \\
\text { Missing }\end{array}$ & $\begin{aligned} 1317(54 \%) \\
720(29 \%) \\
312(13 \%) \\
37(1 \%) \\
70(3 \%)\end{aligned}$ & $\begin{array}{c}37(35 \%) \\
47(44 \%) \\
14(13 \%) \\
1(1 \%) \\
8(7 \%)\end{array}$ & 0.001 & $\begin{array}{l}\text { Ref. } \\
1.22(0.64-2.33) \\
1.43(0.72-2.82) \\
1.16(0.16-8.46)\end{array}$ \\
\hline \multicolumn{5}{|l|}{ Education length } \\
\hline $\begin{array}{l}\text { Primary school } \\
\text { High school } \\
\text { Min. } 2 \text { years at University/college } \\
\text { Missing }\end{array}$ & $\begin{array}{r}389(16 \%) \\
930(38 \%) \\
1029(42 \%) \\
108(4 \%)\end{array}$ & $\begin{array}{c}19(18 \%) \\
32(30 \%) \\
49(46 \%) \\
7(6 \%)\end{array}$ & 0.71 & $\begin{array}{c}\text { Ref. } \\
0.85(0.47-1.54) \\
1.24(0.67-2.29)\end{array}$ \\
\hline \multicolumn{5}{|l|}{ Marital status } \\
\hline $\begin{array}{l}\text { Non-married/-cohabiting } \\
\text { Married/cohabiting } \\
\text { Missing }\end{array}$ & $\begin{array}{c}482(20 \%) \\
1944(79 \%) \\
30(1 \%)\end{array}$ & $\begin{array}{c}15(14 \%) \\
88(82 \%) \\
4(4 \%)\end{array}$ & 0.18 & $\begin{array}{c}\text { Ref. } \\
1.34(0.75-2.39)\end{array}$ \\
\hline \multicolumn{5}{|l|}{ Ethnic background } \\
\hline $\begin{array}{l}\text { Native background } \\
\text { Not native background } \\
\text { Missing }\end{array}$ & $\begin{array}{c}2290(93 \%) \\
142(6 \%) \\
24(1 \%)\end{array}$ & $\begin{array}{c}100(93 \%) \\
5(5 \%) \\
2(2 \%) \\
\end{array}$ & 0.64 & $\begin{array}{c}\text { Ref. } \\
0.98(0.38-2.53)\end{array}$ \\
\hline \multicolumn{5}{|c|}{ Physical activity $30 \mathrm{~min}$, times per week } \\
\hline 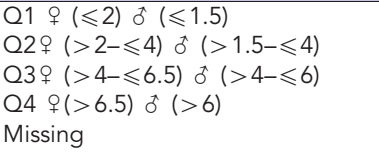 & $\begin{array}{l}549(22 \%) \\
664(27 \%) \\
579(24 \%) \\
555(23 \%) \\
109(4 \%)\end{array}$ & $\begin{array}{c}26(24 \%) \\
25(23 \%) \\
18(17 \%) \\
30(28 \%) \\
8(8 \%)\end{array}$ & 0.73 & $\begin{array}{c}\text { Ref. } \\
0.86(0.48-1.55) \\
0.74(0.38-1.45) \\
1.26(0.69-2.28)\end{array}$ \\
\hline \multicolumn{5}{|l|}{ Alcohol, glasses per week } \\
\hline $\begin{array}{l}\text { Non-drinkers } \\
\text { Q1 } 9(>0-\leqslant 1.15) \text { o }(>0-\leqslant 2) \\
\text { Q2 } 9(>1.15-\leqslant 2) \text { o }(>2-\leqslant 4) \\
\text { Q3 } \text { o }(>2-\leqslant 5) \text { o }(>4-\leqslant 7) \\
\text { Q4 } 9(>5) \text { o }(>7) \\
\text { Missing }\end{array}$ & $\begin{array}{l}463(19 \%) \\
542(22 \%) \\
446(18 \%) \\
497(20 \%) \\
406(17 \%) \\
102(4 \%)\end{array}$ & $\begin{array}{c}20(19 \%) \\
16(15 \%) \\
20(19 \%) \\
20(19 \%) \\
29(27 \%) \\
2(1 \%)\end{array}$ & 0.06 & $\begin{array}{l}1.35(0.67-2.72) \\
\text { Ref. } \\
1.50(0.76-2.96) \\
1.42(0.72-2.83) \\
2.07(1.08-3.96)\end{array}$ \\
\hline \multicolumn{5}{|l|}{ Diet score ${ }^{c}$} \\
\hline $\begin{array}{l}0 \\
1 \\
2 \\
3 \\
\text { Missing }\end{array}$ & $\begin{array}{r}492(20 \%) \\
1021(42 \%) \\
653(27 \%) \\
157(6 \%) \\
133(5 \%)\end{array}$ & $\begin{array}{l}18(17 \%) \\
45(42 \%) \\
32(30 \%) \\
9(8 \%) \\
3(3 \%)\end{array}$ & 0.23 & $\begin{array}{c}\text { Ref. } \\
1.09(0.62-1.91) \\
1.19(0.65-2.19) \\
1.35(0.57-3.19)\end{array}$ \\
\hline \multicolumn{5}{|c|}{ 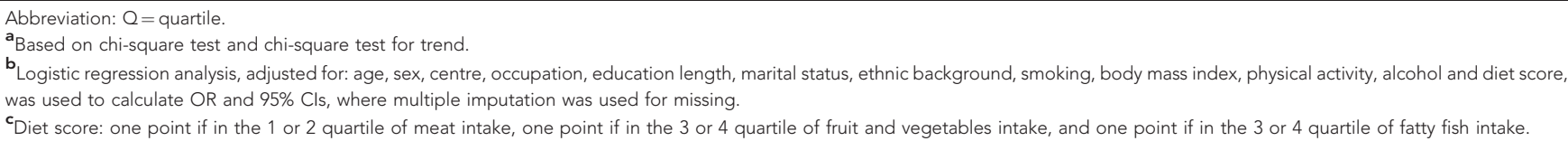 } \\
\hline
\end{tabular}




\section{A}
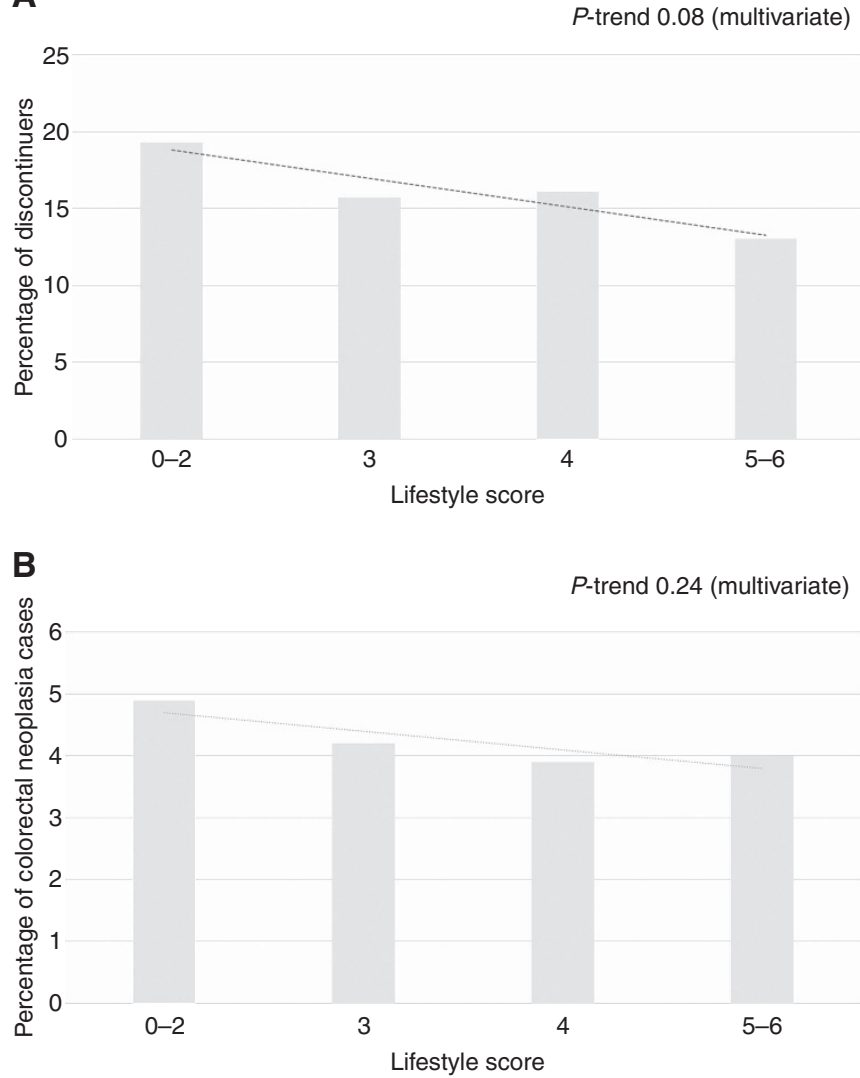

Figure 2. Lifestyle score according to discontinuers and outcome in the second round of faecal immunochemical test. (A) Percentage discontinuing after first round FIT according to lifestyle score ${ }^{a}$ based on health recommendations. P-trend based on multivariate logistic regression. (B) Percentage of colorectal neoplasia cases according to lifestyle score ${ }^{a}$ based on health recommendations. P-trend based on multivariate logistic regression. ' ${ }^{2}$ Lifestyle score received 1 point for each of the following factors: never smoked or smoking cessation $\geqslant 10$ years, BMI (18.5-24.9), physical activity for $30 \mathrm{~min} \geqslant 7$ times per week, consumption of alcohol (women $\leqslant 7$, men $\leqslant 14$ glasses per week), and red and processed meat $\leqslant 4$ times per week. One point was given if the consumption of fruits and vegetables was $\geqslant 3$ per day and fatty fish was $\geqslant 1$ per week. The multivariable logistic regression models were adjusted for: age, sex, screening centre, working status, educational length, marital status, and ethnic background.

first round are scarce and mainly limited to demographic and socioeconomic factors. The results based on the Bowel Cancer Screening Program in England showed that low socioeconomic status, not participating in previous CRC screening, younger age and male gender were associated with discontinuing FOBT screening after the first round (Lo et al, 2015). These findings are similar to the ones in the present study. The results from an Australian study showed that younger age and male gender were associated with a lower likelihood of becoming a dropout in the second round of FIT screening (Cole et al, 2012) in contrast to the present results. The Australian study, however, included participants with both negative and positive first-round FIT screening results in the analysis and did not include information on lifestyle. In another Australian study (Duncan et al, 2014), the results showed that FOBT testing prior to the inclusion in the screening programme was associated with a reduced likelihood of becoming a non-participant in the second round of FOBT screening. Demographic factors associated with non-participation in the first-round FOBT screening (Seeff et al, 2004; Weber et al, 2008;
Blanks et al, 2015; Lo et al, 2015) and first-round FIT screening (Segnan et al, 2007; van Rossum et al, 2008; Hol et al, 2010; Levi et al, 2011; Sali et al, 2016) are similar to those associated with discontinuation of FIT after the first round in our study for age and gender and non-native ethnicity. Unfavorable lifestyle factors such as smoking, overweight, low level of physical activity and low F\&V consumption have been associated with non-participation in the first-round FOBT screening (Weber et al, 2008; Blanks et al, 2015). We found that some of these lifestyle factors also predicted discontinuation of FIT after the first round. We also found that smoking, BMI and high alcohol consumption, which are established lifestyle risk factors for colorectal neoplasia (Botteri et al, 2008; WCRF/AICR, 2011; Ben et al, 2012; Zhu et al, 2014), were associated with detection of colorectal neoplasia at secondround screening in the present study.

Interestingly, low socioeconomic status has been associated with lower risk of CRC in southern Europe but not in the middle and northern Europe (Leufkens et al, 2012). We observed no association between the key socioeconomic variables: education and working status, and discontinuation or colorectal neoplasia in the present study. Socioeconomic status has been associated with lifestyle (Kant, 2004; Knudsen et al, 2014; Markussen et al, 2016), and a recent European rapport suggests that socioeconomic factors explain health inequalities more than behavioural factors (Eikemo et al, 2016). In our population, smoking and obesity were more prevalent in individuals with low education than in individuals with a high education. In spite of this inequality of health behaviours by educational level, lifestyle factors were independently associated with both discontinuation of FIT screening and odds of colorectal adenomas after adjusting for socioeconomic status in the present study. The population in the present study may be more homogenous in socioeconomic factors compared with population-based studies outside the Nordic countries (Leufkens et al, 2012). Consequently, generalisation to populations outside Norway should be done with caution.

The present study has some important strengths. The analyses were based on a large number of observations. Multiple imputation for missing data was used to increase statistical power and reduce bias (Sterne et al, 2009). The random invitation of individuals from the population registry in Norway reduced the risk of selection error. However, our findings have to be interpreted knowing that previous participation in screening is a strong predictor of future CRC screening participation. In our study, $83 \%$ of the first-round participants also participated in the second round, consistent with previous studies (Duncan et al, 2014; Lo et al, 2015). Limitations of the present study include the brevity of the LSQ. The specific questions in the LSQ were copied from other validated questionnaires (Johansson et al, 1998; Norwegian Institute of Public Health, 2016). The LSQ was designed to require $<10 \mathrm{~min}$ to complete, which may have sacrificed details, especially regarding dietary factors. A large number of questions are usually required to assess total dietary consumption. Furthermore, risk of confounding has to be considered in the present study. Results from previous studies have shown self-rated health to be associated with lifestyle and socioeconomic conditions (Molarius et al, 2007), and high BMI has been associated with depression and poor mental health for women (Keddie, 2011; Ul-Haq et al, 2014). The lack of information on self-rated health may have caused some confounding. Additionally, no information on family history of CRC and the use of aspirin/non-steroidal anti-inflammatory drugs might have confounded the results regarding the odds of colorectal neoplasia.

The present results emphasise the importance of collecting information on lifestyle in CRC screening. The lifestyle characteristics associated with discontinuation of FIT-based CRC screening in first-round participants are similar to those associated with the detection of colorectal neoplasia in the present and other studies (Botteri et al, 2008; WCRF/AICR, 2011; Wolin et al, 2011; 
Hong et al, 2012; Aune et al, 2013; Aleksandrova et al, 2014; Ben et al, 2014; Norat et al, 2014; Zhu et al, 2014). Therefore, assessing lifestyle behaviours at screening may help to identify individuals at higher risk for both colorectal neoplasia (Knudsen et al, 2016) and discontinuing FIT-based CRC screening. The present results may help to identify groups of individuals who should be especially encouraged to consistently participate in FIT screening. No existing CRC screening programme uses riskstratifying tests. It may, however, be possible to develop more personalised CRC screening invitations. Non-participants might be resistant to general health messages, and targeted interventions may be required to encourage this subgroup to consistently participate in FIT screening (Weber et al, 2008). Furthermore, the CRC screening setting offers an important opportunity for lifestyle interventions (Anderson et al, 2013), which may contribute to reduction of overall burden of chronic non-communicable diseases.

\section{CONCLUSION}

Discontinuing of FIT screening after the first round was characterised by smoking, morbid obesity and low physical activity. Smoking and morbid obesity were also associated with colorectal neoplasia detected at the second-round FIT screening, along with high alcohol consumption. These results may help in identifying groups of individuals who may benefit by consistent participation in FIT screening.

\section{ACKNOWLEDGEMENTS}

This study was supported by the Norwegian Ministry of Health and Care Services (project number: 2014105).

\section{CONFLICT OF INTEREST}

The authors declare no conflict of interest.

\section{AUTHOR CONTRIBUTIONS}

MDK, PB and EHG collected the data; GH, PB and EB designed the study; $\mathrm{EB}$ and MDK analysed the data; MDK wrote the paper under supervision of TdL, TB, EB, PB and AH. All the authors contributed to the final version of the manuscript.

\section{REFERENCES}

Aleksandrova K, Pischon T, Jenab M, Bueno-de-Mesquita H, Fedirko V, Norat T, Romaguera D, Knuppel S, Boutron-Ruault MC, Dossus L, Dartois L, Kaaks R, Li K, Tjonneland A, Overvad K, Quiros J, Buckland G, Sanchez M, Dorronsoro M, Chirlaque MD, Barricarte A, Khaw KT, Wareham NJ, Bradbury KE, Trichopoulou A, Lagiou P, Trichopoulos D, Palli D, Krogh V, Tumino R, Naccarati A, Panico S, Siersema PD, Peeters P, Ljuslinder I, Johansson I, Ericson U, Ohlsson B, Weiderpass E, Skeie G, Borch K, Rinaldi S, Romieu I, Kong J, Gunter MJ, Ward HA, Riboli E, Boeing H (2014) Combined impact of healthy lifestyle factors on colorectal cancer: a large European cohort study. BMC Med 12(1): 168.

Anderson AS, Mackison D, Boath C, Steele R (2013) Promoting changes in diet and physical activity in breast and colorectal cancer screening settings: an unexplored opportunity for endorsing healthy behaviors. Cancer Prev Res 6(3): 165-172.

Aune D, Chan DS, Vieira AR, Navarro Rosenblatt DA, Vieira R, Greenwood DC, Kampman E, Norat T (2013) Red and processed meat intake and risk of colorectal adenomas: a systematic review and metaanalysis of epidemiological studies. Cancer Causes Control 24(4): 611-627.

Ben Q, An W, Jiang Y, Zhan X, Du Y, Cai QC, Gao J, Li Z (2012) Body mass index increases risk for colorectal adenomas based on meta-analysis. Gastroenterology 142(4): 762-772.

Ben Q, Sun Y, Chai R, Qian A, Xu B, Yuan Y (2014) Dietary fiber intake reduces risk for colorectal adenoma: a meta-analysis. Gastroenterology 146(3): 689-699 e6.

Berstad P, Loberg M, Larsen IK, Kalager M, Holme O, Botteri E, Bretthauer M, Hoff G (2015) Long-term lifestyle changes after colorectal cancer screening: randomised controlled trial. Gut 64(8): 1268-1276.

Blanks RG, Benson VS, Alison R, Brown A, Reeves GK, Beral V, Patnick J, Green J (2015) Nationwide bowel cancer screening programme in England: cohort study of lifestyle factors affecting participation and outcomes in women. Br J Cancer 112(9): 1562-1567.

Botteri E, Iodice S, Raimondi S, Maisonneuve P, Lowenfels AB (2008) Cigarette smoking and adenomatous polyps: a meta-analysis. Gastroenterology 134(2): 388-395.

Brenner H, Kloor M, Pox CP (2014) Colorectal cancer. Lancet 383(9927): 1490-1502.

Bretthauer M, Hoff G (2012) Comparative effectiveness research in cancer screening programmes. BMJ 344: e2864.

Chiu HM, Chen SL, Yen AM, Chiu SY, Fann JC, Lee YC, Pan SL, Wu MS, Liao CS, Chen HH, Koong SL, Chiou ST (2015) Effectiveness of fecal immunochemical testing in reducing colorectal cancer mortality from the One Million Taiwanese Screening Program. Cancer 121(18): 3221-3229.

Cole SR, Gregory T, Whibley A, Ward P, Turnbull D, Wilson C, Flight I, Esterman A, Young GP (2012) Predictors of re-participation in faecal occult blood test- based screening for colorectal cancer. Asian Pac J Cancer Prev 13(12): 5989-5994.

Crotta S, Segnan N, Paganin S, Dagnes B, Rosset R, Senore C (2012) High rate of advanced adenoma detection in 4 rounds of colorectal cancer screening with the fecal immunochemical test. Clin Gastroenterol Hepatol 10(6): 633-638.

de Lange T, Randel KR, Schult AL, Knudsen MD, Kirkøen B, Botteri E, Berstad P, Ursin G, Bretthauer M, Hoff G (2017) Sigmoidoskopi og testing for blod i avføringen - en sammenlignende screeningstudie. Tidsskr Nor Legeforen 10: 727-730

de Wijkerslooth TR, Stoop EM, Bossuyt PM, Meijer GA, van Ballegooijen M, van Roon AH, Stegeman I, Kraaijenhagen RA, Fockens P, van Leerdam ME, Dekker E, Kuipers EJ (2012) Immunochemical fecal occult blood testing is equally sensitive for proximal and distal advanced neoplasia. Am J Gastroenterol 107(10): 1570-1578.

Duncan A, Turnbull D, Wilson C, Osborne JM, Cole SR, Flight I, Young GP (2014) Behavioural and demographic predictors of adherence to three consecutive faecal occult blood test screening opportunities: a population study. BMC Public Health 14: 238.

Eikemo TA, Huijts T, Bambra C, McNamara C, Stornes P, Balaj M (2016) Social Inequalities in Health and their Determinants: Topline Results from Round 7 of the European Social Survey, European Social Survey ERIC, London, UK.

Hol L, van Leerdam ME, van Ballegooijen M, van Vuuren AJ, van Dekken H, Reijerink JC, van der Togt AC, Habbema JD, Kuipers EJ (2010) Screening for colorectal cancer: randomised trial comparing guaiac-based and immunochemical faecal occult blood testing and flexible sigmoidoscopy. Gut 59(1): 62-68.

Hong S, Cai Q, Chen D, Zhu W, Huang W, Li Z (2012) Abdominal obesity and the risk of colorectal adenoma: a meta-analysis of observational studies. Eur J Cancer Prev 21(6): 523-531.

Horton NJ, Lipsitz SR (2001) Multiple imputation in practice: comparison of software packages for regression models with missing variables. Am Stat 55(3): 244-254.

Johansson L, Solvoll K, Bjorneboe GE, Drevon CA (1998) Under- and overreporting of energy intake related to weight status and lifestyle in a nationwide sample. Am J Clin Nutr 68(2): 266-274.

Kant AK (2004) Dietary patterns and health outcomes. J Am Diet Assoc 104(4): 615-635.

Keddie AM (2011) Associations between severe obesity and depression: results from the National Health and Nutrition Examination Survey, 2005-2006. Prev Chronic Dis 8(3): A57.

Kirkegaard H, Johnsen NF, Christensen J, Frederiksen K, Overvad K, Tjonneland A (2010) Association of adherence to lifestyle recommendations and risk of colorectal cancer: a prospective Danish cohort study. BMJ 341: c5504. 
Knudsen MD, de Lange T, Botteri E, Nguyen DH, Evensen H, Steen CB, Hoff G, Bernklev T, Hjartaker A, Berstad P (2016) Favorable lifestyle before diagnosis associated with lower risk of screen-detected advanced colorectal neoplasia. World J Gastroenterol 22(27): 6276-6286.

Knudsen VK, Matthiessen J, Biltoft-Jensen A, Sorensen MR, Groth MV, Trolle E, Christensen T, Fagt S (2014) Identifying dietary patterns and associated health-related lifestyle factors in the adult Danish population. Eur J Clin Nutr 68(6): 736-740.

Larsen IK, Grotmol T, Almendingen K, Hoff G (2006) Lifestyle characteristics among participants in a Norwegian colorectal cancer screening trial. Eur $J$ Cancer Prev 15(1): 10-19.

Leufkens AM, Van Duijnhoven FJ, Boshuizen HC, Siersema PD, Kunst AE, Mouw T, Tjonneland A, Olsen A, Overvad K, Boutron-Ruault MC, Clavel-Chapelon F, Morois S, Krogh V, Tumino R, Panico S, Polidoro S, Palli D, Kaaks R, Teucher B, Pischon T, Trichopoulou A, Orfanos P, Goufa I, Peeters PH, Skeie G, Braaten T, Rodriguez L, Lujan-Barroso L, Sanchez-Perez MJ, Navarro C, Barricarte A, Zackrisson S, Almquist M, Hallmans G, Palmqvist R, Tsilidis KK, Khaw KT, Wareham N, Gallo V, Jenab M, Riboli E, Bueno-de-Mesquita HB (2012) Educational level and risk of colorectal cancer in EPIC with specific reference to tumor location. Int J Cancer 130(3): 622-630.

Levi Z, Birkenfeld S, Vilkin A, Bar-Chana M, Lifshitz I, Chared M, Maoz E, Niv Y (2011) A higher detection rate for colorectal cancer and advanced adenomatous polyp for screening with immunochemical fecal occult blood test than guaiac fecal occult blood test, despite lower compliance rate. A prospective, controlled, feasibility study. Int J Cancer 128(10): 2415-2424.

Lo SH, Halloran S, Snowball J, Seaman H, Wardle J, von Wagner C (2015) Colorectal cancer screening uptake over three biennial invitation rounds in the English bowel cancer screening programme. Gut 64(2): 282-291.

Markussen MS, Veierod MB, Kristiansen AL, Ursin G, Andersen LF (2016) Dietary patterns of women aged 50-69 years and associations with nutrient intake, sociodemographic factors and key risk factors for noncommunicable diseases. Public Health Nutr 19(11): 2024-2032.

Molarius A, Berglund K, Eriksson C, Lambe M, Nordstrom E, Eriksson HG, Feldman I (2007) Socioeconomic conditions, lifestyle factors, and selfrated health among men and women in Sweden. Eur J Public Health 17(2): $125-133$.

Norat T, Aune D, Chan D, Romaguera D (2014) Fruits and vegetables: updating the epidemiologic evidence for the WCRF/AICR lifestyle recommendations for cancer prevention. Cancer Treat Res 159: 35-50.

Nordic Council of Ministers (2012) Nordic Nutrition Recommendations. 5th edn. Nordic Council of Ministers: Copehagen, Denmark.

Norwegian Institute of Public Health (2016) The Oslo Study I and II. Available at: https://www.fhi.no/en/studies/regional-health-studies/theoslo-study-i-and-ii/.

Pornet C, Denis B, Perrin P, Gendre I, Launoy G (2014) Predictors of adherence to repeat fecal occult blood test in a population-based colorectal cancer screening program. Br J Cancer 111(11): 2152-2155.

Sali L, Mascalchi M, Falchini M, Ventura L, Carozzi F, Castiglione G, Delsanto S, Mallardi B, Mantellini P, Milani S, Zappa M, Grazzini G, SAVE Study Investigators (2016) Reduced and full-preparation CT colonography, fecal immunochemical test, and colonoscopy for population screening of colorectal cancer: a randomized trial. J Natl Cancer Inst 108(2): doi:10.1093/jnci/djv319.
Scholefield JH, Moss SM, Mangham CM, Whynes DK, Hardcastle JD (2012) Nottingham trial of faecal occult blood testing for colorectal cancer: a 20-year follow-up. Gut 61(7): 1036-1040.

Seeff LC, Nadel MR, Klabunde CN, Thompson T, Shapiro JA, Vernon SW, Coates RJ (2004) Patterns and predictors of colorectal cancer test use in the adult US population. Cancer 100(10): 2093-2103.

Segnan N, Senore C, Andreoni B, Azzoni A, Bisanti L, Cardelli A, Castiglione G, Crosta C, Ederle A, Fantin A, Ferrari A, Fracchia M, Ferrero F, Gasperoni S, Recchia S, Risio M, Rubeca T, Saracco G, Zappa M, Group-Italy SW (2007) Comparing attendance and detection rate of colonoscopy with sigmoidoscopy and FIT for colorectal cancer screening. Gastroenterology 132(7): 2304-2312.

Steele RJ, McClements PL, Libby G, Carey FA, Fraser CG (2014) Patterns of uptake in a biennial faecal occult blood test screening programme for colorectal cancer. Colorectal Dis 16(1): 28-32.

Sterne JA, White IR, Carlin JB, Spratt M, Royston P, Kenward MG, Wood AM, Carpenter JR (2009) Multiple imputation for missing data in epidemiological and clinical research: potential and pitfalls. BMJ 338: b2393.

The Norwegian Directory of Health (2011) Kostråd for å Fremme Folkehelsen og Forebygge Kroniske Sykdommer, The Norwegian Directory of Health place: Oslo, Norway.

Ul-Haq Z, Mackay DF, Fenwick E, Pell JP (2014) Association between body mass index and mental health among Scottish adult population: a crosssectional study of 37,272 participants. Psychol Med 44(10): 2231-2240.

van der Vlugt M, Grobbee EJ, Bossuyt PM, Bongers E, Spijker W, Kuipers EJ, Lansdorp-Vogelaar I, Essink-Bot ML, Spaander MC, Dekker E (2017) Adherence to colorectal cancer screening: four rounds of faecal immunochemical test-based screening. Br J Cancer 116(1): 44-49.

van Rossum LG, van Rijn AF, Laheij RJ, van Oijen MG, Fockens P, van Krieken HH, Verbeek AL, Jansen JB, Dekker E (2008) Random comparison of guaiac and immunochemical fecal occult blood tests for colorectal cancer in a screening population. Gastroenterology 135(1): $82-90$.

WCRF/AICR (2011) Continuous Update Project Report. Food, Nutrition, Physical Actevity, and the Prevention of Colorectal Cancer. WCRF/AICR (World Cancer Research Fund/American Institute for Cancer Research). Imperial College London: London, UK.

Weber MF, Banks E, Ward R, Sitas F (2008) Population characteristics related to colorectal cancer testing in New South Wales, Australia: results from the 45 and Up Study cohort. J Med Screen 15(3): 137-142.

World Health Organization (2003) Diet, Nutrition and the Prevention of Chronic Diseases. No. 916. WHO: Geneva, Switzerland, pp 149.

World Health Organization (2016) Body Mass Index - BMI. Available at: http://www.euro.who.int/en/health-topics/disease-prevention/nutrition/ a-healthy-lifestyle/body-mass-index-bmi(accessed 29 November 2016).

Wolin KY, Yan Y, Colditz GA (2011) Physical activity and risk of colon adenoma: a meta-analysis. Br J Cancer 104(5): 882-885.

Zhu JZ, Wang YM, Zhou QY, Zhu KF, Yu CH, Li YM (2014) Systematic review with meta-analysis: alcohol consumption and the risk of colorectal adenoma. Aliment Pharmacol Ther 40(4): 325-337.

This work is published under the standard license to publish agreement. After 12 months the work will become freely available and the license terms will switch to a Creative Commons AttributionNonCommercial-Share Alike 4.0 Unported License.

Supplementary Information accompanies this paper on British Journal of Cancer website (http://www.nature.com/bjc) 